\title{
Parents' Experience of Caring Children with Cancer: A Qualitative Study with Phenomenological Approach
}

\author{
Mahin Ahmadi Pishkuhi ${ }^{1,2}$, Mahdieh Ahmadi ${ }^{3}$, Hamidreza Shoraka $^{4}$ and Maryam Chegeni ${ }^{5,6, *}$ \\ ${ }^{1}$ Pars Advanced and Minimally Invasive Medical Manners Research Center, Pars Hospital, Iran University of Medical Sciences, Tehran, Iran \\ ${ }^{2}$ Department of Epidemiology and Biostatistics, School of Public Health, Tehran University of Medical Sciences, Tehran, Iran \\ ${ }^{3}$ Department of Nursing, Karaj Medical Science Branch, Islamic Azad University, Alborz, Iran \\ ${ }^{4}$ North Khorasan University of Medical Sciences, Bojnurd, Iran \\ ${ }^{5}$ Department of Biostatistics and Epidemiology, School of Public Health, Kerman University of Medical Sciences, Kerman, Iran \\ ${ }^{6}$ HIV/STI Surveillance Research Center, WHO Collaborating Center for HIV Surveillance, Institute for Futures Studies in Health, Kerman University of Medical Sciences, \\ Kerman, Iran \\ "Corresponding author: Department of Epidemiology and Biostatistics, School of Public Health, Kerman University of Medical Sciences, Kerman, Iran. Email: \\ mchegeni6@gmail.com
}

Received 2017 December 25; Revised 2018 August 03; Accepted 2018 August 16

\begin{abstract}
Background: Diagnostician of cancer in children can influence their parents' life due to the fact that the disease may threaten the patient's life. It can also put a great burden of care on their parents.

Objectives: In this study, we tried to clear the feelings of parents who experience the phenomenon of caring a child with cancer.

Methods: The present study has been conducted as a qualitative research with phenomenological approach. Participants were selected with purposeful sampling among 13 parents with an average age of 33.2 and we continued sampling until data saturation. Information was collected by in-depth interviews. The process of interviews was valid and acceptable. Finally, data were categorized as content frameworks (themes) and analyzed with the Colizzi method.

Results: The extracted content is consisted of eight main subheadings that include the parents anxiety of the death of their children, parents inability to respond to the questions of their children, parents inability to have an appropriate behavior while confronting the children angry, parents suffering of treatment side effects in their children, the pressure of economic, social, and psychological burden on family, lack of time, experienced the impact of spiritual support, and influence on the relationship between parents and 18 subthemes.

Conclusions: Taking care of a child with cancer may have an influence on the parents' life in different aspects and on their quality of life. Regarding the severity of this experiment on the life of parents and due to the sensitivity of this issue, it seems necessary that the results of this study be considered by the country's health policy makers.
\end{abstract}

Keywords: Qualitative Studies, Pediatrics, Cancer

\section{Background}

In Iran, cancer is known as the third cause of death in adults. According to reports, the incidence of cancer in children has increased in recent years (1). According to a literature review conducted in 2010 on research articles in Iran, the incidence rate of childhood cancer was up to 112 and up to 144 per million among girls and boys (2). Of course, since without developing a pathological sample, many oncologists detect cancer in children, there are not many cases of childhood cancers, and there is little reporting on the statistics on the incidence of childhood cancer (3).

The survival rate of cancer has increased dramatically over the past three decades. Nearly two- thirds of cancer- ous children survive (4), however, it continues to threaten the lives of these children. Nonetheless, death rates in children have decreased, however, the number of children with cancer has increased. The onset of cancer is sudden and unexpected and its treatment may take several years. All of these factors can affect the affected child's family as if their lives were undergoing fundamental changes (5). Caring for the child is a natural attribute of the parent, however, when the child gets diagnosed with the disease that threatens his or her life, the parental care role in providing care becomes wider. Generally, parents of children with cancer experience more crisis than other parents. Due to the effective role of parents in child care, the lack of attention to the biological, psychological, and social problems 
of caring parents can endanger family health and even child health. While by recognizing parental problems, reducing stress and improving parent's ability in their functional and mental crisis management, the health and performance of the family can be improved $(6,7)$.

Among the research carried out by Iranian researchers, we are confronted with a limited number of studies that have explained the qualitative approach to the quality of life of parents caring for children with cancer, however, in the context of the experiences that these parents have in caring for a child with cancer, no study has been done in Iran. The importance of qualitative research is among the experiences that, based on perception and experience, lead to the discovery of concepts that are not usually obtained in the form of quantitative tools.

\section{Objectives}

Therefore, in this study, with our phenomenological approach, we go to the parents 'parental life of these children to understand the parents' experience in caring for a child with cancer and thereby help the health team and health decision-makers to understand their biological and mental status.

\section{Methods}

This is a qualitative study that is conducted in January 2017 with a phenomenology approach, which is a suitable method for providing evidence, a clear and summarized description of the phenomenon is considered as a proper technique (8). The paradigm for this study has been a postpositivist approach.

\subsection{Method of Selecting the Study Participants}

In order to achieve the goal of studying, the selection of participants in the study will begin with a purposeful sampling and will continue until data saturation. Using the gradual sampling method from available samples on weekdays the researcher referred to the target center (Imam Khomeini Hospital's Cancer Department, the Chemotherapy Ward) in Iran and then, after selecting an eligible sample by expressing the purpose and obtaining written consent, interviewed with the parents who have had an experience of having a child cancer. We ensured the study participants that we would keep the interviews confidential. In case the parent was not satisfied to answer the questions, we didn't force them to reply, they were free to end the interview session whenever they wanted. The inclusion criteria in the study included: (1) A family of a cancer child under the age of 15 years; (2) in the family, there should be only one child with cancer and the other family members should not have cancer; (3) the sick child should not have a known chronic disease other than cancer (based on taking a history of the parents and a medical record of the patient). To take into account the variation, interviews with parents, who have been diagnosed with their children, were performed at different stages of the disease.

\subsection{Data Collection}

To collect data, in-depth interviewing was used in this study. The method of doing the work was an individual interview that was conducted in a private and guided manner by the researcher in an in-depth manner. The interview time was adjusted in coordination with the participants, and usually, the duration of each interview was 40 minutes to one hour and recorded and transcribed with the consent of the participant. If necessary, the continuation of the interview would be postponed. The second turn of the interview was arranged in order to complete the information gathered from each participant and clarify the vague points of the previous statements. Furthermore, information on age, gender, ethnicity, and so on were recorded, which were only used to better describe participants. After the first interview and handwriting of the information, the material was considered in terms of being incomplete or obscure. A quiet room in the hospital was devoted to the interview. The questions raised in the interview were:

What you feel about your current life compared with before?

What problems have you encountered when your child was diagnosed with cancer?

What do you think is good for your own situation and your family?

What is your experience about the care team?

What is important in your everyday life?

Has your attitude about yourself, others, and the world affected this experience? If yes, how?

Then, the interview continued also by relying on the questions that emerged in an interaction between the interviewer and interviewee and to achieve deeper information regarding the exploratory questions, such as "explain more", or "say more precisely what you said", were used.

\subsection{Data Collection Tool}

In phenomenology, the main method of collecting data is a deep interview and the researcher can also complete the information box by viewing the field attendees, as well. 


\subsection{How to Analyze Data}

After each interview, the tape was extracted, and to reassure, the tape of data was extracted again, and then, it was adapted to their original text. We used the Colaizzi method to analyze the data. At this stage, the raw content of the data was categorized, coded, and their "main themes" were extracted. Meaning units were specified and condensed with a description similar to the text. Then, a list of codes is prepared, and by meaning revising, determining the differences and similarities in the meaning of the same codes in a reduction and induction form, was inserted in a more abstract level. Thus, we obtained the acceptable subclasses and classes (9).

\subsection{To Ensure the Study's Trustworthiness}

To confirm the study validation, several criteria were considered; including study credibility, dependability, and confirmability. We spent enough time doing this study and the method of the study was checked by two epidemiologists. In all procedures of the study, details were noted and recorded to ensure the confirmability of findings. In addition, two study members codified the interviews separately to ensure that they had a similar opinion, and to ensure the validity of the study, the member checking method was used so that browsing manuscript was done by the participants to confirm the extracted content. Finally, we used the peer debriefing method and used two experts' idea regarding the findings of our study.

\section{Results}

In total, 13 parents taking care of a child with cancer participated in the interview, on average, two years after the diagnosis of cancer in their children. Parents participating in the study were 27 to 43 years with a mean age of 33.2 years, all of whom were married except one. The results of the interviews extracted were carefully reviewed and the responses were categorized in the form of concepts in order to identify the experiences of parents in caring for a child with cancer. The extracted themes include eight main themes: parent's concern about their child's death, the inability of parents to answer their children's questions, the inability of parents to deal adequately with child aggression, the discomfort and suffering of parents from the complications of treatment, the burden of economic, social, and psychological difficulties with family, lack of time, parents' experienced the impact of spiritual support on their feeling: as well as an influence on the relationship between parents. Eighteen subthemes were extracted that are showed in Box 1.

\begin{tabular}{|c|}
\hline Themes and Subthemes \\
\hline Parental concern about their child's death \\
\hline Feeling hopeless for treatment of their children \\
\hline Effects on mental and sleep of parents \\
\hline The inability of parents to answer their children's questions \\
\hline $\begin{array}{l}\text { The inability of parents to answer questions about the reason of their } \\
\text { children diseased }\end{array}$ \\
\hline $\begin{array}{l}\text { The inability of parents to answer their children's questions about } \\
\text { death }\end{array}$ \\
\hline Parents' inability to deal adequately with child aggression \\
\hline Inability to deal with child fights with her associates \\
\hline $\begin{array}{l}\text { Inability to deal with child aggression for scream of the white nurses' } \\
\text { clothes }\end{array}$ \\
\hline Inability to deal with child aggression for resisting in eating the drug \\
\hline $\begin{array}{l}\text { Parents' inconvenience and suffering from the complications of the } \\
\text { treatment }\end{array}$ \\
\hline $\begin{array}{l}\text { Parents suffering from children's hair loss as a complications of the } \\
\text { chemotherapy }\end{array}$ \\
\hline $\begin{array}{l}\text { Parents suffering from children's nauseous and vomiting as a } \\
\text { complications of the chemotherapy }\end{array}$ \\
\hline Parents didn't like to force children for treatment \\
\hline The economic, social, and psychological problems' burden on the family \\
\hline The economic pressure on the family due to direct and indirect costs \\
\hline $\begin{array}{l}\text { The psychological problems on the family due to change of mood, } \\
\text { being ill-tempered, being nervous and sensitive }\end{array}$ \\
\hline Lack of time \\
\hline Lack of time to spend for other family members \\
\hline Lack of time for pleasure activities \\
\hline Parents' experienced the impact of spiritual support on their feeling \\
\hline Experience of prayer and trust in God had a good effect on their feelings \\
\hline $\begin{array}{l}\text { Experience of emotional support from their spouse, other children, } \\
\text { and first class families had a good effect on their feelings }\end{array}$ \\
\hline Effects or outcomes of child disease on relationships between parents \\
\hline Problems have arisen between couples \\
\hline The correlation of couples increased \\
\hline
\end{tabular}

\subsection{Parental Concern About Their Child's Death}

Many parents expressed a great deal of frustration with their child's recovery, and some thought the disease was led to death and expressed a great deal of concern. Parent code 1 said, "At first I did not believe at all that my child had been diagnosed with cancer, but since he became worse, I constantly think about losing him, and I cannot sleep from this thought and concern at night... I have repeatedly asked God to give me death instead of him". 
4.2. The Inability of Parents to Answer Their Children's Questions

The parents spoke on questions that their sick children asked about illness and death. The answer to some of these philosophical questions has been difficult for parents, such as “do I go to paradise after death?", "If I die, can I still see you (my mother and father)?", "If I promise to be a good boy, I will not die anymore?" (mother of a 7-yearold child), "Has God put on sickness and pain to punish my mistakes?” (mother of a 10-year-old child)

\subsection{Parents' Inability to Deal Adequately with Child Aggression}

Most of the interviewed parents were agonizing in regards to their child due to a sickly illness, and even one parent acknowledged that the pain and presence in the hospital caused her child to scream constantly and fight with her associates (mother of a 6-year-old child). Another mother said that her child was resisting and aggressive in eating the drug, and another parent said, "my son is afraid of the white nurses' clothes, and when they see them next to his bed, he gets nervous".

\subsection{Parents' Inconvenience and Suffering from the Complica- tions of the Treatment}

"My daughter is worried about her hair loss", "after every chemotherapy, my child becomes ill for up to a week... nauseous and vomiting so much that I'm tormented". "At the previous chemotherapies, my child got so bad that now when she sees that she must undergo chemotherapy once again she fights with me, we had to force her to be prepared for treatment because she is anxious". "My daughter is ashamed of her hair loss, and she is not attended among the population and playing with other kids, she worries that the rest will laugh at her... so she hides from the people".

\subsection{The Economic, Social, and Psychological Problems' Burden on the Family}

Caring for a child with cancer imposes a lot of costs to their families. The cost of the provision of medicine, diet, hospitalization, and transport put economic pressure on the family. In addition, indirect costs, such as reduced working hours, resulting in reduced earnings, loss of livelihood, and loss of job opportunities are imposed on parents and family. One of the mothers said, "before my child became sick, I was employed, but I cannot go to work because of her care and treatment". One of the fathers also said: "I am self-employed and I cannot spend enough time working because of my business and so my income has fallen... but family spending has risen for hospitals and medications... in general, income, and expenses are not well-matched".

One of the participants said, "since my child has been ill, my mood has been changed... I've been ill-tempered... I get nervous quickly and scream.... I'm very sensitive to my associates' behaviors. I get my heart out even trivial behaviors... I feel I'm so less severe".

\subsection{Lack of Time}

Due to the hospitalization of the child in the hospital as well as the care of the sick child at home, most mothers have been forced to change their lifestyle. They need to spend a lot of time and energy in caring for the sick child and have less time for themselves. For example, one of the parents said: "I am always involved with the hospital and keeping the patient... If my mother did not support us, my other children could not go to school and stay. My mother filled the void left by my absence for them". "Since I was involved with my childhood illness, I really do not have the time to play the role of a housewife... I used to be an obsessive person, but now my home and my life are in a different situation and I cannot even take care myself".

Previously, we always went to parties and spent time with relatives and acquaintances, but now, we have no time at all for our leisure... even when we do not have time for a break. "Unlike in the past, I cannot handle myself, my husband, and my life. It's really hard for me".

\subsection{Parents' Experienced the Impact of Spiritual Support on Their Feeling}

By different statements, the majority of parents referred to their experience of prayer and trust in God increased their tolerance against the problem. For example, the mother of a 6-year-old child said: "Whatever God wants is the same... I've trusted god and I keep mentioning him... All my friends and relatives also pray for my child's health... I hope that the blessing of these prayers will cause my child to be healed".

One of the fathers said: "Since my son's disease has been diagnosed, I have not missed my treatment... I have seen the best doctors and I've done everything I could, but he will not be cured until God's will”.

One of the mothers said: "I do not have the patience to see my child's pain and suffering... whenever I'm despair and restless, I calm down myself by prayer, because God has said in the Qur'an, with the remembrance of God, the hearts become calm... I believe that the only one who can save my child from illness is God. So, always at the height of despair, I ask for help from him, and sometimes I vow".

Parents also referred to experience of spiritual and emotional support from their spouse, other children, 
and first-class families. Most mothers said that receiving emotional support from relatives had been soothing and hearty for them. The experience of receiving promising sentences, family members' sympathy, being perceivable by relatives was one of the things that had a good effect on parents. For example, one of the mothers said: "Sometimes I cry out and I'm so depressed that I confined myself in my room and I do not like to be in touch with anyone... If my wife and my parents did not give me comfort, I do not know how I adapted myself to these conditions. "Another mother said: "My wife stands standing like a mountain behind me and my child and does not hesitate to do anything... If we didn't have her encouragement, I would not survive alone under the pressure of my child disease".

\subsection{Effects or Outcomes of Child Disease on Relationships Be- tween Parents}

Parental relationships change in the face of a child's illness. In some families, the disease has been shown to increase the correlation of couples and, in some cases, problems have arisen between them. One of the mothers said, "my husband is more patient than me and always tries to hope that our child will be good... but I'm nervous and aggressive when I see my child suffering and sometimes I'm very sad to fight with him...." He always calls me calmly, but once told me that it was tired of seeing this situation, and if I continue to do this, it gets discouraged from me". "One of the mothers said: "Since we found out that our child has cancer, the relationship between me and my wife has changed... although we are often tired and marital relationships are dimmed, the emotional relationship between us is strengthened and our relationship is in a new direction.... In my opinion, in such problems, it becomes clear how much the husband and wives are behind each other".

One of the initial reactions to the diagnosis of cancer in children was that parents had been looking for a cause for the disease in their child. One of the mothers said: "My husband always smoked at home and blamed him for the first time and fought with him".

\section{Discussion}

The present study aimed to investigate the experiences of parents of children with cancer regarding the pressure of caring a diseased child on the family body. In this study, there were themes about the experiences of the parents of cancer children.

\subsection{Parental Concern About the Death of Children}

One of the most important themes extracted is the issue of parents' concern about the death of their child. An issue that takes away all their mind and energy. The unpredictable nature of the illness and the lack of confidence in treatments, especially in caring mothers, have led to a decrease in the quality of life of parents (10). In the Willis' study, the initial response of parents after a definitive diagnosis of leukemia was the fear and panic that all over there was due to the fact that they considered cancer as the impending death (11). Duncan and Melman et al. consider the feeling of losing a child as the biggest and worst problem of parents (12). The Jadidi et al. study also stated that all participants in their study spoke of the absolute despair of surviving their child, and due to their negative perception, they considered cancer as equal to death, they were reluctant to survive (13).

\subsection{The Inability of Parents to AnswerTheir Children's Questions}

In this study, parents encountered questions from their children that were not easily able to respond to them such as questions about death and afterward, including what is death? According to a study by van der Geest et al. who looked at parents' perceptions of talking about death with a child with cancer in 2015, parents described the reasons for their reluctance to talk to their sick child about death. One of them is the inability of parents to talk about death that is imminent. Some parents have said they do not see the power to tell their child that they have an incurable illness. A number of parents said they would not be able to cope with their child's death or hope to treat their sick child. Some also said that they were afraid of reactions such as anger or sadness from their child (14).

\subsection{Parents' Inability to Deal Adequately with Child Aggression}

Children were sometimes not aware of the pain caused by aggressive disease, parents often did not know how to deal adequately with them. According to a study by ReisiDehkordi et al., parents and children with cancer face challenges such as aggression, depression, and anxiety. Among the behaviors associated with child aggression, such as screaming and shouting, the avoidance of eating drugs is mentioned. After taking the medication, they even talked violently and aggressively with the treatment team and their parents. Children, when they were not interested in it, screamed and evacuated themselves (15). According to this study, the lack of knowledge and psychological problems are one of the most important problems of their patients and their mothers. Therefore, giving enough information about the disease, treatment, and complications for children and their parents is necessary. Similarly, the implementation of some mental interventions can reduce psychological problems, such as aggression (15). Special and specialized education of psychology to parents can 
create the necessary capabilities to identify the source of their child's aggressive behavior and manage it.

\subsection{Discomfort and Suffering Due to Treatment Complications}

Children suffered from complications such as hair loss, nausea, vomiting, and loss of appetite due to treatment, such as chemotherapy. These complications had a negative effect on the mood of children and their parents.

Several studies have shown that chemotherapy is the worst patient experience during the treatment period (16). These studies have shown that chemotherapy, as an aggressive and severe treatment causes unwanted problems such as a decrease in quality of life and disturbances in the functioning of parents and children. Problems with pain, hair loss, fatigue, dyspnea, and anorexia are the most problematic experiences during the treatment period from the parents' point of view $(15,17-23)$. Therefore, appropriate interventions are needed to reduce the complications of treatment.

\subsection{The Burden of Economic, Social, Psychological Problems on the Family}

In this study, there were problems with the economic problems caused by the disease such as medical expenses, job losses, and unemployment due to full-time care of the patient's child, emotional and psychological stress, and depression of the parents due to attending a hospital, in which their child was admitted, was one of the problems expressed by parents. In a study by Jadidi et al., the parents of children with leukemia, among from their experiences and problems, pointed to economic, social, and family problems.

In many other studies, the socioeconomic burden of cancer and higher and heavier costs of treatment have been noted. Some parents have pointed to the loss of job opportunities, reduced income, and their loss of savings. The longtime hospitalization of children leads to a lot of psychological problems in the patient and his family, which has been repeatedly reported by the parents of the children in various studies (24-26).

\subsection{Lack of Time}

The results of this study showed that many parents were faced with a lack of time to look after themselves or their children and social activities due to full-time care. This is well seen in other studies. Therefore, numerous studies in Canada, China (Hong Kong), Brazil, and Iran have shown that parents are well in attendance with their sick child in order to take care of him or her and have more peace of mind and full participation in their child's treatment $\operatorname{arm}(13,27-29)$.
Parents' experienced the impact of spiritual support on their feeling: This study shows that parents who are caregivers stated that they experienced a better feeling with prayer and spiritual support, and they felt less disappointed.

Various studies have shown that faith in God leads to better adaptation to illness and decreases frustration (30, 31). In various studies, the remembrance of God has been raised as a way to reduce fear and anxiety (17). Similarly, in a study, Doumit and Khoury explores the facilitating factors that parents of cancer patients experience in order to deal with their child's cancer. He showed that strong religious beliefs are among the most influential factors (26).

\subsection{Effects or Outcomes of Child Disease on Relationships Be- tween Parents}

In this study, the burden of taking care of a child with illness has shown different effects in families. In some cases, the incidence of childhood cancer has led to an inconsistency between the parents. While in other families, empathy between parents has increased due to the maintenance of a sick child, we can also point out the limitation of marital relationships, due to the thought of parents involved in the care and treatment of their children. Several other studies have shown positive and negative effects of caring for a cancerous child for families, relationships between family members and spouses (29, 32, 33). In this period, the attention of parents focuses on various emotional, physical, and psychological aspects of their sick child. They are sympathetic to overcoming their child's disease, however, they are separated as a couple, their role seems to have changed completely, and they are experiencing a new life (33-35). Studies have shown that the high level of stress, anxiety, and constant concern about childhood disease on the one hand and the geographical, emotional, and physical deprivation of the parents, on the other hand, reduces the intimacy and marital satisfaction, and increases physical and mental tiredness as well as decreases the quality of life (35-37).

Evidence obtained from the findings of this study show the detail of the experiences of parents who care for a child with cancer. Findings can help policymakers at the macro level to plan for suitable interventions. It should be noted, however, that phenomenological studies, despite the fact that they have a certain essence, that the generalizability of the findings is limited.

\subsection{Conclusions}

Given the severity of the impact of this experience on the lives of patients' families and the sensitivity of the subject, we recommend measures such as the entire covering 
of this category of children by insurance, taking measures for more leave or reducing the working hours of parents of cancer patients, the presence of a psychologist in the hospital to counsel parents with regard to the emotional relationships among family members, as well as training in dealing with the child or how to respond appropriately to their child. Therefore, it is necessary that the results of this study be considered in the field of health policy.

\section{Acknowledgments}

This research has been supported by Tehran University of Medical Sciences and health Services grant. The authors would like to thank the epidemiology and bostatistics of the Research Development Center of Sina Hospital for their technical assistance.

\section{References}

1. Mousavi SM, Gouya MM, Ramazani R, Davanlou M, Hajsadeghi $\mathrm{N}$, Seddighi Z. Cancer incidence and mortality in Iran. Ann Oncol. 2009;20(3):556-63. doi: 10.1093/annonc/mdn642. [PubMed: 19073863].

2. Mousavi SM, Pourfeizi A, Dastgiri S. Childhood cancer in Iran.J Pediatr Hematol Oncol. 2010;32(5):376-82. doi: 10.1097/MPH.0b013e3181e003f7. [PubMed: 20588194].

3. Mosavi-Jarrahi A, Moini M, Mohagheghi MA, Alebouyeh M, Yazdizadeh $B$, Shahabian A, et al. Clustering of childhood cancer in the inner city of Tehran metropolitan area: A GIS-based analysis. Int J Hyg Environ Health. 2007;210(2):113-9. doi: 10.1016/j.ijheh.2006.08.005. [PubMed: 17008129].

4. Stam H, Grootenhuis MA, Last BF. The course of life of survivors of childhood cancer. Psychooncology. 2005;14(3):227-38. doi: 10.1002/pon.839. [PubMed: 15386772].

5. Cantrell MA, Conte TM. Between being cured and being healed: The paradox of childhood cancer survivorship. Qual Health Res. 2009;19(3):312-22. doi: 10.1177/1049732308330467. [PubMed: 19224875].

6. Mendenhall AN, Mount K. Parents of children with mental illness: Exploring the caregiver experience and caregiver-focused interventions. Fam Soc-J Contemp Soc Serv. 2018;92(2):183-90. doi: 10.1606/10443894.4097.

7. McCubbin MA, Huang STT. Family strengths in the care of handicapped children: Targets for intervention. Fam Relat. 1989;38(4):436. doi: $10.2307 / 585750$

8. Elo $\mathrm{S}$, Kyngas $\mathrm{H}$. The qualitative content analysis process. J Adv Nurs. 2008;62(1):107-15. doi: 10.1111/j.1365-2648.2007.04569.x. [PubMed: 18352969].

9. Starks H, Trinidad SB. Choose your method: A comparison of phenomenology, discourse analysis, and grounded theory. Qual Health Res. 2007;17(10):1372-80. doi: 10.1177/1049732307307031. [PubMed: 18000076].

10. Khanjari S, Oskouie F, Eshaghian Dorche A, Haghani H. Quality of life in parent of children with leukemia and its related factors. Iran J Nurs. 2013;26(82):1-10.

11. Wills BS. The experiences of Hong Kong Chinese parents of children with acute lymphocytic leukemia.J Pediatr Nurs. 1999;14(4):231-8. doi: 10.1016/S0882-5963(99)80017-7. [PubMed: 10467801].

12. Kerr LM, Harrison MB, Medves J, Tranmer J. Supportive care needs of parents of children with cancer: Transition from diagnosis to treatment. Oncol Nurs Forum. 2004;31(6):E116-26. doi: 10.1188/04.ONF.E116E126. [PubMed: 15547626].
13. Hekmatpou D, Eghbali A, Memari F. [The experiences of parents of children with leukemia: A qualitative research]. Arak Med Univ J. 2013;15:28-40. Persian.

14. van der Geest IM, van den Heuvel-Eibrink MM, van Vliet LM, Pluijm SM, Streng IC, Michiels EM, et al. Talking about death with children with incurable cancer: Perspectives from parents. $J$ Pediatr. 2015;167(6):1320-6. doi: 10.1016/j.jpeds.2015.08.066. [PubMed: 26427964].

15. Reisi-Dehkordi N, Baratian H, Zargham-Boroujeni A. Challenges of children with cancer and their mothers: A qualitative research. Iran J Nurs Midwifery Res. 2014;19(4):334-9. [PubMed: 25183971]. [PubMed Central: PMC4145485].

16. Pishkuhi MA, Salmaniyan S, Nedjat S, Zendedel K, Lari MA. Psychometric properties of the Persian version of satisfaction with care EORTCin-patsat32 questionnaire among Iranian cancer patients. Asian Pac J Cancer Prev. 2014;15(23):10121-8. [PubMed: 25556436].

17. Sajadian A, Montazeri A. [Exploring the experiences of Iranian women with breast cancer: A qualitative study]. Iran JEpidemiol. 2011;7(2):8-16. Persian.

18. Latha SM, Scott JX, Kumar S, Kumar SM, Subramanian L, Rajendran A. Parent's perspectives on the end-of-life care of their child with cancer: Indian perspective. Indian J Palliat Care. 2016;22(3):317-25. doi: 10.4103/0973-1075.185047. [PubMed: 27559262]. [PubMed Central: PMC4973494].

19. Rahimi S, Fadakar Soghe R, Tabri R, Kazemnezhad leili E. [Related factors with quality of life among preschool children with cancer]. $J$ Holist Nurs Midwifery. 2014;24(1):30-9. Persian.

20. Kvist SBM, Rajantie J, Kvist M, Siimes MA. Perceptions of problematic events and quality of care among patients and parents after successful therapy of the child's malignant disease. Soc Sci Med. 1991;33(3):249-56. doi: 10.1016/0277-9536(91)90358-j.

21. von Lutzau P, Otto M, Hechler T, Metzing S, Wolfe J, Zernikow B. Children dying from cancer: Parents' perspectives on symptoms, quality of life, characteristics of death, and end-of-life decisions. JPalliat Care. 2012;28(4):274-81. [PubMed: 23413763].

22. Heath JA, Clarke NE, Donath SM, McCarthy M, Anderson VA, Wolfe J. Symptoms and suffering at the end of life in children with cancer: An Australian perspective. Med J Aust. 2010;192(2):71-5. [PubMed: 20078405].

23. Hechler T, Blankenburg M, Friedrichsdorf SJ, Garske D, Hubner B, Menke A, et al. Parents' perspective on symptoms, quality of life, characteristics of death and end-of-life decisions for children dying from cancer. Klin Padiatr. 2008;220(3):166-74. doi: 10.1055/s-2008-1065347. [PubMed: 18478489].

24. Syse A, Larsen IK, Tretli S. Does cancer in a child affect parents' employment and earnings? A population-based study. Cancer Epidemiol.2011;35(3):298-305. doi: 10.1016/j.canep.2010.08.002. [PubMed: 20822964].

25. Boling W, Macrina DM, Clancy JP. The caregiver quality of life cystic fibrosis (CQOLCF) scale: Modification and validation of an instrument to measure quality of life in cystic fibrosis family caregivers. Qual Life Res. 2003;12(8):1119-26. [PubMed: 14651429].

26. Doumit MAA, Khoury MN. Facilitating and hindering factors for coping with the experience of having a child with cancer: A Lebanese perspective. J Psychosoc Oncol. 2017;35(3):346-61. doi: 10.1080/07347332.2017.1283654. [PubMed: 28098505].

27. Lam LW, Chang AM, Morrissey J. Parents' experiences of participation in the care of hospitalised children: A qualitative study. Int J Nurs Stud. 2006;43(5):535-45. doi: 10.1016/j.ijnurstu.2005.07.009. [PubMed: 16143333].

28. Ames KE, Rennick JE, Baillargeon S. A qualitative interpretive study exploring parents' perception of the parental role in the paediatric intensive care unit. Intensive Crit Care Nurs. 2011;27(3):143-50. doi: 10.1016/j.iccn.2011.03.004. [PubMed: 21511474]. 
29. Silva-Rodrigues FM, Pan R, Pacciulio Sposito AM, de Andrade Alvarenga W, Nascimento LC. Childhood cancer: Impact on parents' marital dynamics. Eur J Oncol Nurs. 2016;23:34-42. doi: 10.1016/j.ejon.2016.03.002. [PubMed: 27456373].

30. O'Connor AP, Wicker CA. Clinical commentary: Promoting meaning in the lives of cancer survivors. Semin Oncol Nurs. 1995;11(1):68-72. doi: 10.1016/s0749-2081(95)80045-x.

31. Overcash JA. Using narrative research to understand the quality of life of older women with breast cancer. Oncology Nursing Forum. 2004;31(6).

32. Ljungman L, Boger M, Ander M, Ljotsson B, Cernvall M, von Essen L, et al. Impressions that last: Particularly negative and positive experiences reported by parents five years after the end of a child's successful cancer treatment or death. PLoS One. 2016;11(6). e0157076. doi: 10.1371/journal.pone.0157076. [PubMed: 27272318]. [PubMed Central: PMC4896617].

33. Kars MC, Duijnstee MS, Pool A, van Delden JJ, Grypdonck MH. Be- ing there: Parenting the child with acute lymphoblastic leukaemia. J Clin Nurs. 2008;17(12):1553-62. doi: 10.1111/j.1365-2702.2007.02235.x. [PubMed: 18482117].

34. Woodgate RL. A different way of being: Adolescents' experiences with cancer. Cancer Nurs. 2005;28(1):8-15. [PubMed: 15681977].

35. Schweitzer R, Griffiths M, Yates P. Parental experience of childhood cancer using interpretative phenomenological analysis. Psychol Health. 2012;27(6):704-20. doi: 10.1080/08870446.2011.622379. [PubMed: 22149644].

36. Khoury MN, Huijer HA, Doumit MA. Lebanese parents' experiences with a child with cancer. Eur J Oncol Nurs. 2013;17(1):16-21. doi: 10.1016/j.ejon.2012.02.005. [PubMed: 22456333].

37. Steffen BC, Castoldi L. [Surviving the storm: The influence of the oncologic treatment of a child on the conjugal relation]. Psicol Ciência Profissão. 2006;26(3):406-25. Spanish. doi: 10.1590/s141498932006000300006. 